\title{
DEBILIDADES HERMENÉUTICAS Y EDUCACIÓN POST-CRÍTICA
}

\section{Hermeneutical weaknesses and post-critical Education}

\author{
Anna PAGÈS SANTACANA \\ Universidad Ramon Llull. España. \\ annaps@blanquerna.url.edu \\ bttp://orcid.org/0000-0001-6033-0333
}

Fecha de recepción: 01/02/2020

Fecha de aceptación: 15/03/2020

Fecha de publicación en línea: 01/07/2020

\section{RESUMEN}

En este comentario sobre el Manifiesto por una Pedagogía Post-crítica nos preguntamos por el lugar desde dónde se organiza la exposición del texto, cuestionando algunas confusiones filosóficas que problematizan su propuesta, como el malentendido sobre qué es la Pedagogía Crítica. En un segundo momento analizamos lo que el Manifiesto denomina "hermenéutica pedagógica" desde la perspectiva del giro ontológico llevado a cabo por Hans-Georg Gadamer en Verdad y Método (1960).

Palabras clave: teoría de la educación; hermenéutica; filosofía de la educación; pedagogía crítica.

\section{ABSTRACT}

In this commentary on the Manifesto for a Post-critical Pedagogy we interrogate the text from the place where it has been organized, putting into question some philosophical confusions which problematized its proposal, mainly a misunderstanding of what Critical Pedagogy is. In a second moment we analyse what the Manifesto calls "Pedagogical Hermeneutics» from the perspective of the ontological turn carried out by Hans-Georg Gadamer in Truth and Method (1960).

Key words: educational theory; hermeneutics; philosophy of education; critical pedagogy. 


\section{INTRODUCCIÓN}

El contenido y propósito del Manifiesto por una Pedagogía Post-crítica ${ }^{1}$ de Naomi Hodgson, Joris Vlieghe, y Piotr Zamojski, escrito en septiembre de 2016 y expuesto en la Liverpool Hope University en octubre del mismo año se presenta, inicialmente, con un formato ajeno al campo de la interrogación filosófica. Desde el punto de vista de la Filosofía de la Educación, es posible afirmar que la forma, estructura y enfoque de un Manifiesto pone en duda el propósito esencial de la tarea filosófica. Esta consiste en cuestionar la realidad e interrogarla para localizar su verdad, ya sea en forma única o múltiple. En cambio, un Manifiesto realiza una declaración afirmativa, rehúye las preguntas, expone lo que habría que hacer. Un Manifiesto enmascara el interrogante o la duda, no permite titubear. Evita, en general, referirse al lugar desde donde fue escrito. Se trata de una declaración de principios supuestamente explícita pero cuya intención, en realidad, sería eludir el debate de las ideas fundamentales encubiertas en el texto. El Manifiesto es en general un brazo armado de la política. ¿De qué política hablamos en este caso?

Tradicionalmente, y desde las orientaciones clásicas marxista y neo-marxista, un Manifiesto propone transformar la sociedad. Sin embargo, la paradoja inicial de este Manifiesto es que pretende criticar el neomarxismo (en su derivación llamada teoría crítica) utilizando, precisamente, uno de los formatos clásicos de dicha perspectiva, consecuencia no solo de la posición de Marx en su Manifiesto Comunista de 1848, sino también de una lectura posterior a la obra de este autor (en particular desde la primera y segunda generación de la Escuela de Frankfurt). Por esa misma razón, aunque este documento se titule Manifiesto, su contenido parece querer impugnar la idea misma de un Manifiesto: contribuir a transformar una práctica social establecida, en este caso, la práctica de la educación y la conceptualización filosófica que la acompaña. Como muy claramente definió Max Horkheimer:

Las reglas empíricas no son otra cosa que las formulaciones de nuestro saber acerca de las relaciones económicas, sociales y psicológicas. (...) Tanto la fructuosidad, para la transformación del conocimiento presente, de las conexiones empíricas que se van descubriendo, como su aplicación a los hechos, son determinaciones que no se reducen a elementos puramente lógicos o metodológicos sino que, en cada caso, solo pueden ser comprendidas en su ligazón con procesos sociales reales. (1990, pp. 228-229).

Por lo tanto, este Manifiesto, aunque parecería decir lo contrario, tiene una intención política que mueve un interés ligado a procesos sociales reales. Sin embargo, se presenta como otra cosa, arguyendo que el formato Manifiesto tiene más relación con la Filosofía Analítica anglosajona que con el marxismo, y evitando referirse al paradigmático Manifiesto Comunista de Marx y Engels cuya conocida

1. La versión española que se cita en este artículo forma parte del monográfico «Una respuesta iberoamericana al 'Manifiesto por una pedagogía post-crítica'»: http://dx.doi.org/10.14201/teri.22862 
frase inicial dice así: «Un fantasma recorre Europa: es el fantasma del comunismo.» Pero más adelante —esto es crucial— prosigue: "Ya es tiempo de que los comunistas expongan abiertamente ante todo el mundo su enfoque, sus objetivos, sus tendencias, oponiendo a la leyenda del fantasma del comunismo un manifiesto de su propio partido.» (Marx y Engels, 1998, p. 38).

¿Cuál es el fantasma al que hace referencia este Manifiesto post-crítico? ¿Cuál es la perspectiva que oponen a la «leyenda» de la pedagogía crítica? ¿En qué términos la exponen abiertamente?

En el comentario al documento en su versión inglesa, Tyson E. Lewis (2017, pp. 23-33) interroga haber seleccionado la modalidad de un Manifiesto para, aparentemente, manifestarse en contra de lo que un Manifiesto propone en sí mismo, esto es: denunciar el orden establecido e impulsar un cambio político y social. Si un Manifiesto refleja una ideología en el sentido marxista, es decir, una idea militante que pasa a la acción, a la movilización, para impactar el statu quo garante de la injusticia o de la opresión, ¿̇ónde está la idea militante en este Manifiesto en particular, cuál es el motor que lo propulsa a la acción? El supuesto de la neutralidad no tiene ya adeptos en un mundo física e intelectualmente agotado como el que vivimos.

La cuestión del formato del documento es un síntoma evidente de un problema de mayor calado, relacionado con la inconsistencia teórica del texto, que voy a definir aquí con el término "posición ficticia". Se puede usar esta expresión como sinónimo de ideología, en el sentido marxista más clásico, es decir: una idea que encubre una determinada práctica con la finalidad de reproducirla intacta en el tiempo, es decir, con la pretensión de perpetuarla o conservarla. Una posición ficticia se define también como una dificultad para pensar sobre el significado filosófico de lo que está en juego. En el sentido freudiano del término, se trataría de una modalidad de la denegación (Verneinung). La posición ficticia no siempre es problemática: lo es cuando, como en este caso, reduce el lenguaje a un instrumento de esquematización y el debate a una mera una declaración de principios con una mínima elaboración teórica.

¿Cuál es la finalidad de este documento? Parece claro que se trata de sustituir algunos supuestos de la Pedagogía Crítica (o de la crítica a la Pedagogía). Pero ¿desde dónde tiene lugar esta operación? ¿Cuál es el orden del discurso? ¿Qué contenido le da forma y estructura? No parece que el Manifiesto pueda dar cuenta de estas preguntas de forma explícita o reveladora para el lector. Parafraseando a H. G. Gadamer, podríamos afirmar que el Manifiesto no define bien cuáles son los pre-juicios que causaron su concepción, redacción y posterior difusión-debate.

En el presente comentario crítico a un documento post-crítico, me permito realizar, en primer lugar, algunas observaciones preliminares que resumen algunas confusiones conceptuales del texto. En un segundo momento voy a centrarme en la cuestión del uso incorrecto que el Manifiesto hace del concepto "Hermenéutica» en su relación con la Pedagogía. Este me parece ser el principal escollo del texto. 


\section{OBSERVACIONES PRELIMINARES}

\subsection{El oximoron de la temporalidad en Filosofía}

Es evidente que no existe, filosóficamente hablando, una temporalidad lineal o cronológica según la cual afirmemos que una orientación filosófica determinada está superada en el sentido del uso del prefijo "post». Como cuando decimos postestructural, post-moderno o postfeminista. La concepción de una temporalidad lineal vertebrada en el progreso de las ideas, unas más recientes que superan a otras más remotas, no puede ya sostenerse desde el punto de vista filosófico e incluso psicológico o histórico. El concepto de progreso fue en su momento impugnado por autores de la Filosofía contemporánea como Heidegger, Benjamin o Derrida. Por esa razón, resulta cuestionable o azaroso añadir el adjetivo post-crítico al sustantivo educación en el título del Manifiesto. La Filosofía de la Educación, como la Filosofía en general, se despliega en el tiempo de manera circular, retrotrayendo los grandes temas (la verdad, la justicia, el bien, la educación), recapitulando desde el presente la posibilidad de actualizar un pasado en diálogo permanente con la posibilidad del futuro. En este sentido, no se puede decir que la educación pueda llegar a ser "post-crítica» o "pre-crítica" porque, en cada presente y de manera simultánea, en dialéctica constante, a través de las temáticas que en cada momento se plantean, relacionadas con las circunstancias históricas, estarán en juego las grandes perspectivas filosóficas. Por tanto, no es posible proponer una distribución cronológica en una sola dirección hacia delante a propósito de qué, en qué momento y desde qué perspectiva resulta adecuado abordar las preguntas filosóficas sobre qué es educación, su contenido y finalidades. Cada época replantea las cuestiones de siempre desde nuevos términos y perspectivas desde nuevos retos y dificultades. Para la Filosofía no existe una superación de puntos de vista como tampoco una respuesta definitiva a las preguntas. A diferencia del discurso de la ciencia o la tecnología, para las que el progreso es una realidad (en campos como la Biomedicina, la Física Cuántica, las telecomunicaciones...) la reflexión filosófica resulta siempre extraña a la idea de una evolución progresiva hacia adelante. Así pues, la pregunta ¿qué es educar? se formula permanentemente, no se termina de resolver, aunque sí varían los términos de su planteamiento en coyunturas teóricas y prácticas distintas para cada momento histórico.

\subsection{Confusión entre Normas y Principios}

El texto del Manifiesto utiliza de manera confusa los términos normas (o normatividad) y principios. Reduce conceptualmente los principios a las normas en una especie de falacia naturalista forzada. 
Las normas constituyen una formalización concreta para una práctica inspirada por un principio. El principio puede entenderse como un ideal, es decir, una idea alimentada por una ilusión. El Manifiesto dice al respecto lo siguiente:

hay principios que defender. Lo cual, en sí mismo, no nos compromete con nada más allá, es decir, no nos compromete a tener que hacer "X". No se trata de afirmar la normatividad en el sentido de definir un estado ideal, presente o futuro, contra el cual debiera juzgarse la práctica actual. Por lo tanto, este principio podría caracterizarse como la defensa de un giro que nos lleve desde una normatividad de procedimientos hacia una normatividad de principios.

La confusión surge en la afirmación «un giro que nos lleve desde una normatividad de procedimientos hacia una normatividad de principios». El error del punto de vista contemporáneo consiste en reemplazar los principios por la normatividad, es decir, reducir la práctica compartida de los principios, su múltiples expresiones o concreciones, a una mera normatividad. El Manifiesto considera que la normatividad de principios es distinta a la normatividad de procedimientos. Se podría entender que con esta expresión propone, por ejemplo, criticar el reduccionismo tecnológico que sufre la experiencia educativa en el mundo contemporáneo. Sin embargo, los significantes norma y principio están mal combinados con lo que se convierten en un oxímoron. Las normas no coinciden en ningún caso con una ley simbólica universal. La ley simbólica da sentido a la globalidad pero no se reduce al conjunto de las pequeñas incidencias, de su aplicación múltiple, cuyos intentos por coincidir con el principio que las inspira fracasan sistemáticamente, abriéndose en cambio a diversos efectos de significación. Los principios de la ley simbólica determinan la incidencia en el mundo de una perspectiva más amplia (que puede ser a la vez más o menos absoluta, eterna o inmutable en el sentido platónico, aunque no únicamente). Un ejemplo de ley simbólica es la prohibición del incesto que Lévi-Strauss estudió desde la Antropología Estructural. Pero también se entiende por ley simbólica un código moral como los diez mandamientos o las bienaventuranzas en el Evangelio. La ley simbólica, sus principios acerca de qué es admisible y qué no, es irreductible a un conjunto de normas sobre cómo hacer. Siguiendo a Jacques Derrida (1993), decir «normatividad de principios» sería como reducir la noción de justicia al conjunto de leyes susceptibles de ser modificadas en distintos contextos políticos. Dicho de otro modo, el principio — como la justiciaes irreductible al conjunto de normas — como las leyes- que pretenden reflejarlo en las distintas situaciones de la práctica. Hablar de normatividad de principios es una manera de invertir la lógica de los principios que inspiran pero no determinan las normas, transformándolos así en una forma de determinación. En todo caso el Manifiesto debería decir: "pasar de la hegemonía de las normas a la prevalencia simbólica de los principios.» 


\subsection{Crítica ingenua a la Pedagogía Crítica}

El documento hace una crítica ingenua a la Pedagogía Crítica, a la que acusa de mirar demasiado lo que no funciona y no ser suficientemente optimista. Dicha afirmación representa en sí misma un wishful thinking totalmente alejado de la reflexión filosófica rigurosa. Al contrario: la Teoría y la Pedagogía Críticas constituyen en sí mismas y en sus distintas formulaciones (desde Marx hasta la segunda generación de la Escuela de Frankfurt) aproximaciones utópicas que imaginan un mundo no solo más justo y equitativo, sino un mundo cuya relación con la verdad termine por encajar, un mundo en cierta forma "transparente a sí mismo» que habrá desvelado al final cualquier enmascaramiento ideológico, un mundo que aspira a la emancipación como una realidad posible. Así lo señala Freire (2005, p. 40): «Humanización y deshumanización, dentro de la historia, en un contexto real, concreto y objetivo, son posibilidades de los hombres como seres inconclusos y conscientes de su inconclusión."

¿Tal vez este exceso de idealismo por parte de la Pedagogía Crítica pudiera ser cuestionado? Sin embargo, el Manifiesto parecería defender una idea opuesta. Para justificar que la Pedagogía Crítica focaliza sus esfuerzos en los problemas más que en las soluciones el documento subraya que la educación «se funda en la esperanza de lo que aún está por venir». La debilidad de este razonamiento es directamente proporcional a la obviedad que pretende defender. En efecto: no hay ninguna teoría pedagógica que afirme lo opuesto a la idea de un mundo mejor por venir. La teoría crítica no es una excepción. Por otra parte, la Pedagogía se construye desde sus inicios como una modalidad del discurso fundacionalmente optimista. Por lo tanto: oponer el optimismo de una pedagogía post-crítica al pesimismo de la pedagogía crítica que la precedería constituye una operación intelectualmente tramposa. Favorecería la simplificación de los términos y diluiría su complejidad.

\section{DEBILIDADES HERMENÉUTICAS}

En este apartado vamos a comentar una de las tesis centrales del Manifiesto que dice así:

Aquí partimos de la asunción de que podemos hablar y actuar — juntos- y, por lo tanto, pasar de la pedagogía hermenéutica que conlleva la pedagogía crítica, a defender una - segundo principio- hermenéutica pedagógica. Son los desafíos que representa vivir juntos en un mundo común los que constituyen la esperanza que hace que la educación siga pareciendo una actividad que merece la pena. La hermenéutica no como un problema (irresoluble), sino como algo que el educador necesita crear.

La hermenéutica filosófica, desde Hans-Georg Gadamer (en Verdad y Método, 1988) hasta Hans Blumenberg (en su Teoría del mundo de la vida, 2013) plantea un giro ontológico. Esto significa entender la comprensión como una categoría 
existencial, una condición de posibilidad del conocimiento en el sentido kantiano más que un método para conocer la realidad. La tesis básica de la hermenéutica gadameriana es que la Historia, el Arte y la Literatura (podríamos añadir en la serie la experiencia de la educación) conducen al ser humano a una verdad que tiene valor, aunque no se trate de la verdad de la ciencia.

Se puede pensar en la actualidad de la hermenéutica como Filosofía de la Educación (Pagès, 2005, 2016) recuperando tres temas fundamentales para la Pedagogía: a) la historicidad, entendida como el impacto de la historia en nuestras biografías; b) la tradición, en su dimensión de pre-juicio respecto del que debemos posicionarnos pero del que no podemos deshacernos; c) la comprensión como una modalidad de diálogo en el lenguaje. El debate entre Verdad y Método (Gadamer, 1988) y Conocimiento e Interés (Habermas, 1965) tuvo lugar alrededor de estos tres conceptos pero, fundamentalmente, alrededor de la función de la tradición en la producción teórica y filosófica. Mientras que para Habermas cualquier tradición es sospechosa de enmascarar un interés encubierto, generalmente orientado a perpetuar un orden institucional y político injusto (por lo tanto ideológico en el sentido marxista clásico), Gadamer propondrá una relación con la tradición menos desconfiada y más reflexiva. No se trata de sospechar sistemáticamente de toda tradición por el hecho de serlo sino de tomar conciencia de su impacto en nuestro modo de ver el mundo. Entender de qué manera la tradición forma parte de nosotros y qué queremos hacer con ello. Por otra parte, cuando el Manifiesto dice "la pedagogía hermenéutica que conlleva la pedagogía crítica «¿de qué está hablando? No hay pedagogía hermenéutica que conlleve una pedagogía crítica, porque se oponen frontalmente respecto de qué hacer con la herencia cultural (acogerla para reflexionar sobre sus efectos históricos en Gadamer; discutirla sistemáticamente para terminar impugnándola en Habermas).

Entonces, desde el punto de vista de la Hermenéutica Filosófica, se podría afirmar que la educación, transmisora de valores, ideas, lenguaje y herencia cultural, emprende un doble propósito: por una parte, conducir al educando al lugar del saber heredado a través de la instrucción; por otra inspirar una interrogación sobre el saber heredado simbólicamente productiva, abriendo nuevos significados, permitiendo otras lecturas y ampliando la perspectiva de sentido:

La reflexión hermenéutica propuso recibir la tradición de una manera activa. Gadamer se sintió interpelado por su propia tradición, defendiendo con fuerza la idea de la historicidad como un tipo de conciencia histórica: «un momento nuevo dentro de lo que siempre ha sido la relación humana con el pasado. (Pagès, 2016, p. 47).

Así pues, la hermenéutica no puede ser reducida a un simple método pedagógico: la "pedagogía hermenéutica" incluye la hermenéutica como horizonte teleológico, al nivel de las finalidades educativas que dan sentido a la propia práctica. Sin embargo, no es posible hablar de una hermenéutica pedagógica, porque la hermenéutica no puede transformarse, bajo ningún concepto (so pena de convertirse en un 
simple instrumento) en una norma o en una prescripción. Siguiendo a Fullat (1984) podemos diferenciar entre la Pedagogía como un discurso prescriptivo, la teoría de la educación como un discurso descriptivo y la Filosofía de la Educación como un discurso crítico o interrogativo (crítico en el sentido kantiano del vocablo griego krinein, separar, distinguir). Así pues, cuando el Manifiesto propone "pasar de una pedagogía hermenéutica a una hermenéutica pedagógica» plantea una contradictio in terminis. Si definimos la Pedagogía como una ciencia normativa de la educación, cuyo objetivo es prescribir el modo en que debe organizarse y ser llevado a cabo el acto de educar, en el sentido del deber-ser, resulta imposible plantear la hermenéutica como una Pedagogía, porque lo que precisamente la caracteriza en calidad de Filosofía de la educación es su condición irreductible a toda prescripción o norma que dirija una acción. Al contrario, el giro ontológico de la hermenéutica de Gadamer propone precisamente revertir la idea de la hermenéutica como un mero método, a pesar de la riqueza y complejidad de sus aplicaciones conocidas en el ámbito de la religión, el derecho y la música o la literatura. Aunque, históricamente el método se ha desarrollado desde una determinada práctica y contexto, no solo existe la interpretación como técnica. Dicho de otro modo, para Gadamer la aplicación de la hermenéutica como método demuestra su razón de ser porque básicamente «Somos» interpretación a lo largo de nuestra experiencia histórico-biográfica. Cuando Gadamer critica la empatía en el enfoque de las Ciencias del Espíritu de Dilthey (Gadamer, 1988, pp. 277-305) está defendiendo esta idea de la comprensión como lo que hace al ser que comprende, sin con ello abarcar de un modo absoluto lo que debería ser comprendido (esto es, el lenguaje) por el peso de la historicidad que limita la capacidad de conocimiento del ser humano. La hermenéutica no es, pues, un camino (metodológico) que conduzca a captar una esencia del ser sino más bien una obertura del ser mismo del lenguaje. En esta obertura se produce un juego dialéctico de interrogación, una conversación que permite el surgimiento de significados no desvelados:

(...) también el fenómeno hermenéutico encierra en sí el carácter original de la conversación y la estructura de pregunta y respuesta. El que un texto transmitido se convierta en objeto de la interpretación quiere decir para empezar que plantea una pregunta al intérprete. La interpretación contiene en esta medida una referencia esencial constante a la pregunta que se le ha planteado. (Gadamer, 1988, p. 447).

Por eso también, usando un ejemplo de la literatura, Gadamer afirmará: «el Aquiles de Homero es más que su modelo original.» (1988, p. 159). En esta frase encontramos lo esencial de la obertura al significado en la hermenéutica como aplicación.

Subrayemos en el Manifiesto otro punto del párrafo que dedica a la hermenéutica. Dice así: "La hermenéutica no como un problema (irresoluble) sino como algo que el educador necesita crear.» Esta frase parece interesante, pero da la impresión de estar mal formulada. La hermenéutica no es un problema irresoluble 
en sí mismo sino una forma de relación histórico-filosófica con el saber y su efecto de verdad en el sujeto que comprende. Tiene que ver con las formas de interpretar la realidad desde una obertura a posibles sentidos. ¿Qué quiere decir el Manifiesto cuando afirma que la hermenéutica es «algo que el educador necesita crear»? ¿Por qué medios y desde qué posición el educador puede crear hermenéutica y por qué? Esta frase no se entiende bien y tal vez necesitaría una mejor explicación. ¿Se refiere al sentido como una modalidad de interrogación existencial, una cuestión que falla actualmente en lo que Lluís Duch denominó crisis gramatical o desempalabramiento del mundo?

En mi artículo "Actualidad de la Hermenéutica como Filosofía de la Educación» (Pagès, 2016, p. 50) destaqué este punto en particular, denominándolo precariedad simbólica. La precariedad simbólica consiste en una desarticulación entre la palabra y el mundo de referencia. Rescatar el sentido de la palabra orientada al mundo que se enfrenta a ella, en su dificultad constitutiva para decir qué hay, resulta esencial en un contexto como el actual, en el que la aceleración, el impacto de la tecnología, el individualismo, han mermado sustancialmente las posibilidades expresivas (lingüísticas y comunicativas) del ser humano. En su antropología simbólica, Lluís Duch subrayó la importancia del símbolo como un modo de hacer presente lo ausente. En un mundo donde la ausencia cada vez es más difícil de aceptar, de entender y mucho más de expresar, decir que "el educador necesita crear la hermenéutica" resultaría sugerente para señalar a la Pedagogía caminos de introducción del símbolo en su discurso y sus prácticas. La frase "crear la hermenéutica» se podría, entonces, interpretar como una forma de restitución del trabajo del símbolo, apuntado por E. Cassirer (1967) en su Antropología Filosófica al definir al ser humano como un animal symbolicum. En efecto, la hermenéutica podría ser una manera de enfrentar la precariedad simbólica del mundo contemporáneo, que impacta en la posibilidad de recrear la palabra y restituir la conversación a los contextos educativos.

No obstante, el Manifiesto acusa a la teoría crítica (bajo la forma del post-estructuralismo o la filosofía postmoderna - ise puede usar este término de un modo tan general?-) de plantear que no se puede conocer completamente al otro. Dice así:

En la teoría de la educación, el pensamiento postestructuralista y postmoderno a menudo se han entendido en términos de políticas de identidad, a lo cual ha seguido una preocupación por la otredad, la alteridad y la voz. El respeto al otro y a la diferencia requieren que el educador acepte que nunca podemos conocer completamente al otro. Cualquier intento de hacerlo constituye, por así decirlo, una forma de «violencia» hacia el otro. De ahí que las posibilidades de actuar y de hablar estén suspendidas.

Justamente, la hermenéutica filosófica plantea que no se puede conocer del todo al otro, porque el sentido de su presencia en el mundo, de su punto de vista, de su lectura de la realidad, está incluido en la tradición que le enmarca y la historicidad que le limita, convirtiendo, pues, la interpretación del quién y el qué del otro en un permanente ensayo sobre los significados imbricados en toda experiencia 
humana. ¡Por supuesto que no se puede conocer por completo al otro! Si fuéramos capaces de ello, nos situaríamos más allá del espacio y el tiempo humanos, jugaríamos a ser dioses o lo que es peor, haríamos un mal uso de la aspiración a la verdad como desvelamiento siempre precario. Resulta extraordinario que el Manifiesto critique esta idea, que no podemos conocer del todo al otro, y además la incluya en el punto de vista de lo que denomina, con una falta de precisión rayando el panfleto, el postestructuralismo y el pensamiento posmoderno. ¿Se refiere a Nietzsche, a Vattimo, a Lyotard, a Butler, a Habermas? Por otra parte, es completamente falso afirmar que el postestructuralismo (¿qué autores estarían aquí incluidos? ¿Por qué no se dice claramente?) plantee que no se puede conocer al otro. La posmodernidad, embarcada en la así llamada "crisis del sujeto" (derivada del planteamiento nietzschiano según P. Ricoeur, 1983) efectivamente sitúa al sujeto dividido en el centro de toda alteridad o relacionalidad. Sin embargo, no afirma que el conocimiento del otro sea imposible ni tampoco que, en aras del respeto a la diferencia, no se pueda intentar conocer al otro, mucho menos considerar tal intento como una violencia. ¿Se puede adivinar en este párrafo una referencia a los multiculturalismos en educación? Y si así fuera, ¿no son precisamente las situaciones educativas de contacto cultural, de pluralismo, las que permiten entender qué significa, in situ, ensayar la experiencia existencial de conocer al otro, desde nuestras propias condiciones o cosmovisión? Algunas afirmaciones del texto dejan al lector boquiabierto y perplejo, porque no se entiende bien qué pretende pero además, lo que produce un cierto temor es que tampoco se termina de ver bien si lo que pretende es éticamente aceptable, al presentar como una verdad aglutinante lo que de facto y en la producción filosófica de los últimos años responde a distintos puntos de vista, teorías, conceptos y autores. El Manifiesto opone dos bloques a los que supone una posición filosófica homogénea, sin ningún matiz o connotación y sin especificar qué abarca cada uno de ellos. Además, en el mismo párrafo las ideas se contradicen: por ejemplo, afirmar que la comunalidad no puede ser un a priori sino que se construye a posteriori es, justamente, un supuesto de la teoría crítica, y también del existencialismo de principios del siglo XX, ilustrado por la paradigmática frase de Jean-Paul Sartre (Sartre, 1973, p. 2) "la existencia precede a la esencia.» Otro claro ejemplo de ello es la referencia a J. Rancière ubicándolo en el tránsito de lo crítico a lo post-crítico. Rancière no ha dejado nunca de ser un filósofo crítico cuya obra denuncia la injusticia y la desigualdad en las formas de producción económica y social. Por otra parte, cuando se afirma defender la pedagogía post-crítica (supuestamente no anti-crítica, aunque el texto en su globalidad parezca indicar todo lo contrario) el Manifiesto dice:

Esta recuperación implica dejar de establecer una relación crítica —-tratando de desvelar lo que realmente está sucediendo- o una relación instrumental —mostrando a los educadores qué deben hacer-, para crear un espacio de pensamiento que permita 
que la práctica tenga lugar de nuevo. Esto significa (re)establecer nuestra relación con las palabras, abriéndolas a cuestionamientos, (...).

Ningún cuestionamiento es neutral: responde a una perspectiva, una idea del mundo, un pre-juicio que orienta el sentido que se da a la pregunta. Abrir las palabras a cuestionamientos implica necesariamente atender la realidad más allá de lo que aparenta y, por lo tanto, enunciando qué no marcha en ella, dónde está la falla que divide lo que creemos saber y entender con lo que verdaderamente está en juego. ¿Qué es pensar, sino un ejercicio topográfico de localización? De descripción pormenorizada, de análisis, de interrogación, con el fin de mover, desplazar, desenquistar lo que aparentemente está claro, porque es así, está ahí, en su impávida y ficticia existencia.

Proteger y cuidar son movimientos de la crianza y de la delicadeza que debe presidir toda relación humana. Sin embargo, no son prácticas incompatibles con la verdad como "alétheia» (descubrimiento) o como desenmascaramiento. Lo serían si, al modo de Platón en el Libro VII de La República, creyéramos haber descubierto la luz del sol, el mundo de las ideas eternas, absolutas e inmutables, para convencer sin premura a los demás de nuestra verdad, la que estamos seguros de haber visto. Sin embargo:

La Filosofía de la Educación constituye un acercamiento perplejo e incompleto de la razón interpretativa a la realidad educativa, a partir de los principios o preguntas que subyacen al discurso, la práctica y las propuestas pedagógicas en determinados contextos culturales e históricos (por lo tanto finitos). (Pagès, 2016, p. 43).

En educación, hay que ser cauto. Se mueven muchas piezas en un tablero de alta complejidad. Algunas pueden producir una auténtica catástrofe. Véase lo que pasó durante los fascismos en Europa, tan lejos y sin embargo tan cerca de nuestras miserias económico-sociales actuales. Aunque pensar excesivamente en el pasado a menudo no ayuda a entender el presente, debemos recordar que la lógica de la unilateralidad o la política de bloques, dondequiera que se haga, conducen a maniqueísmos por desgracia demasiado familiares en la historia de Occidente.

\section{ConCluSión}

El Manifiesto por una Pedagogía Post-Crítica es un texto provocador y ambiguo. No obstante, su fundamentación filosófica adolece de una importante falta de rigor. Utiliza el prefijo "post» en la expresión Pedagogía post-crítica para atacar la Pedagogía crítica con argumentos falsos: por un lado, dice querer superarla sin oponerse a ella; pero por otro pretende impugnarla sin especificar qué, quién, cuándo ni cómo. Los principios que dice defender se convierten en armas de doble filo para aglutinar conceptos imprecisos y mal definidos. La esperanza no es exclusiva de ninguna teoría de la educación porque, en la medida en que imaginamos un mundo mejor 
para todos, nos alimentamos de un optimismo fundacional del que participar es una condición necesaria (aunque no determinante) para que el horizonte de la justicia y el bien convierta la experiencia educativa en una práctica hermenéutica de sentido.

\section{REFERENCIAS BIBLIOGRÁFICAS}

Blumenberg, H. (2013). Teoría del mundo de la vida. México: Fondo de Cultura Económica. Cassirer, E. (1967). Antropología Filosófica. México: Fondo de Cultura Económica.

Duch, L. (2019). Vida cotidiana y velocidad. Barcelona: Herder.

Freire, P. (2005). Pedagogía del oprimido. México: Siglo XXI.

Fullat, O. (1984). Verdades y Trampas de la Pedagogía. Barcelona: CEAC.

Derrida, J. (1993). Spectres de Marx. Paris: Galilée.

Gadamer, H. G. (1988). Verdad y Método. Salamanca: Sígueme.

Habermas, J. (1965). Conocimiento e interés. Madrid: Taurus.

Hodgson, N., Vlieghe, J. y Zamojski, P. (2017). Manifesto for a Post-critical Pedagogy. London: Punctum Books. Recuperado de: https://punctumbooks.com/titles/manifesto-for-a-postcritical-pedagogy/ (Consultado el 01/03/2020).

Horkheimer, M. (1990). Teoría tradicional y teoría crítica. En Autor, Teoría Crítica (pp. 223-271). Buenos Aires: Amorrortu.

Marx, K. y Engels, F. (1998). El Manifiesto Comunista. Barcelona: Crítica.

Pagès, A. (2005). Bases hermenèutiques de l'educació. Vers una lectura pedagògica de HansGeorg Gadamer. Temps d'Educació, (29), 167-188.

Pagès, A. (2006). Debilidades hermenéuticas. Pensar la tradición. En Autor, Al filo del pasado. Filosofía hermenéutica y transmisión cultural (pp. 171-217). Barcelona: Herder.

Pagès, A. (2007). Fer justicia a la historicitat de la comprensió. Ars Brevis, 13, 242-257. Recuperado de: https://www.raco.cat/index.php/ArsBrevis/article/view/104621/130891 (Consultado el 02/05/2020).

Pagès, A. (2016). Actualidad de la hermenéutica como filosofía de la educación. Revista Española de Pedagogía, 74(264), 39-55. Recuperado de: https://revistadepedagogia.org/lxxiv/ no-264/actualidad-de-la-hermeneutica-como-filosofia-de-la-educacion/101400001911/ (Consultado el 02/05/2020)

Ricoeur, P. (1983). Temps et récit. Paris: Seuil.

Sartre, J. P. (1973). El existencialismo es un humanismo. Buenos Aires: Sur. 